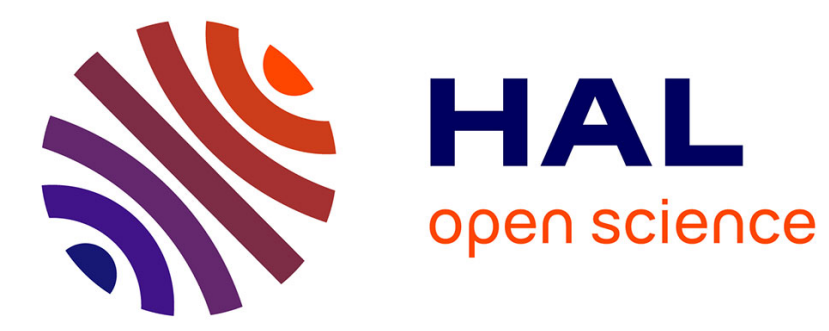

\title{
On the atomic configuration of EL2
}

D. Stievenard, H.J. von Bardeleben

\section{- To cite this version:}

D. Stievenard, H.J. von Bardeleben. On the atomic configuration of EL2. Revue de Physique Appliquée, 1988, 23 (5), pp.803-807. 10.1051/rphysap:01988002305080300 . jpa-00245884

\section{HAL Id: jpa-00245884 https://hal.science/jpa-00245884}

Submitted on 1 Jan 1988

HAL is a multi-disciplinary open access archive for the deposit and dissemination of scientific research documents, whether they are published or not. The documents may come from teaching and research institutions in France or abroad, or from public or private research centers.
L'archive ouverte pluridisciplinaire HAL, est destinée au dépôt et à la diffusion de documents scientifiques de niveau recherche, publiés ou non, émanant des établissements d'enseignement et de recherche français ou étrangers, des laboratoires publics ou privés. 


\title{
On the atomic configuration of EL2
}

\author{
D. Stievenard ( $\left.{ }^{(}\right)$and H. J. von Bardeleben ( $\left.{ }^{2}\right)$ \\ ( $\left.{ }^{1}\right)$ Département de Physique des Solides, Institut Supérieur d'Electronique du Nord, 41, boulevard Vauban, \\ 59046 Lille Cedex, France \\ $\left({ }^{2}\right)$ Groupe de Physique des Solides de l'Ecole Normale Supérieure, Université Paris VII, Tour 23, 2 place \\ Jussieu, 75251 Paris Cedex 05, France
}

(Reçu le 15 juillet 1987, accepté le 15 octobre 1987)

\begin{abstract}
Résumé. - La configuration atomique du défaut EL2 dans son état stable est attribuée à un complexe composé d'un antisite d'arsenique et d'un interstitiel d'arsenique en position de deuxième voisin. Les propriétés de l'état métastable peuvent être décrites dans un modèle d'une paire d'arsenique (As-As $)_{\mathrm{Ga}}$ à un site gallium.
\end{abstract}

\begin{abstract}
The atomic configuration of the EL2 defect in its stable state has been determined as an arsenic antisite defect associated with an arsenic interstitial at a next nearest neighbour site. The metastable EL2 state is tentatively assigned to an arsenic pair defect at a gallium lattice site (As-As) $)_{\mathrm{Ga}}$.
\end{abstract}

\section{Introduction.}

Since its first detection as a native electron trap in LEC, HB and VPE grown GaAs the EL2 defect has been the object of numerous studies [1, 2]. Electrical measurements in semiconducting $\mathrm{GaAs}$ have allowed to determine the thermal [3-5] and optical [6] electron and hole emission cross-sections of this defect and led to the observation of an optically induced transition into a metastable state [7]. The important question of its atomic configuration, both for its stable or metastable state, could however not be answered from these results and led to many complementary studies by different techniques such as optical absorption [8,9], photoluminescence [1, 2] and electron paramagnetic resonance $[10,11]$. The difficulty which arose was to verify that each technique really probed the same defect, EL2, even though eventually in different charge states. In most cases the metastability phenomena have been taken to be sufficient but sometimes concentration criteria have been added. An additional complication stems from the fact that the electrical measurements and in particular the often applied DLTS technique by which this defect is defined, permit to observe this defect only in a few $\mu \mathrm{m}$ thick interface layer of a diode of a Schottky structure which usually has been submitted to thermal treatments in the $400^{\circ} \mathrm{C}$ tempe-

\footnotetext{
REVUE DE PHYSIQUE APPLIQUÉE. - T. 23, N` 5, MAI 1988
}

rature range to allow the establishment of electrical contacts. Optical absorption and EPR measurements on the other hand look at the averaged bulk properties of a crystal with typical $\mathrm{mm}^{3}$ dimension. Evidently, such a complicated situation has been found to be full of traps.

Recently, however, the microscopic identification of EL2 has made an important progress. The first step was a one-to-one correlation between the EL2 defect and the arsenic antisite defect in LEC grown GaAs [11]. Subsequently, we proposed an atomic model for this defect in its stable configuration [12, 13] (Fig. 1): the associated defect of an $\mathrm{As}_{\mathrm{Ga}}$ and an interstitial $\mathrm{As}_{\mathrm{i}}$ ion on a second nearest neighbour site which we have deduced from an extensive DLTS and EPR study on thermally annealed and electron irradiated LEC grown GaAs. Revisiting all the existing experimental data in the light of this model allowed us further to put forward a model for the metastable configuration of EL2 [14] : a nearest neighbour $\mathrm{As}_{\mathrm{Ga}}-\mathrm{As}_{\mathrm{i}}$ pair formed as a result of a Coulomb interaction.

Very recently reinterpreted ENDOR results [15, 16] on the $\mathrm{As}_{\mathrm{Ga}}$ defect in LEC grown GaAs led to the same conclusion that is, the $\mathrm{As}_{\mathrm{Ga}}$ defect is associated with a $\mathrm{As}_{\mathrm{i}}$ ion on a second nearest neighbour tetrahedral interstitial site in the [111] direction. Our model has been further analysed in a 


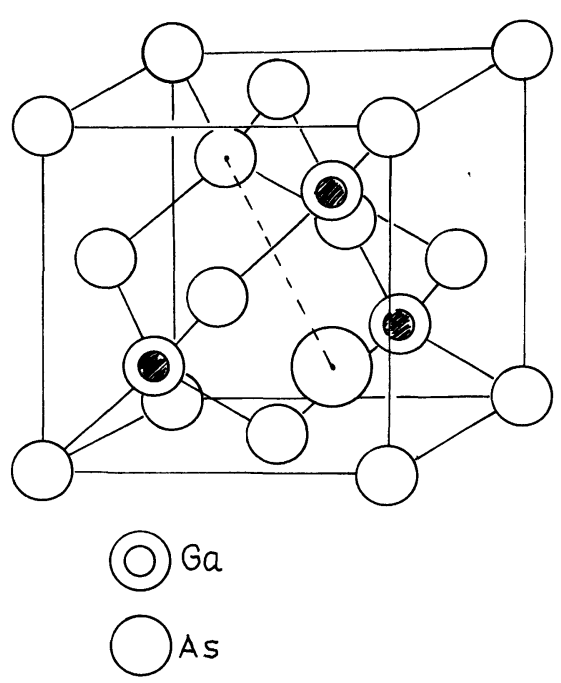

Fig. 1.

Green's function calculation of the electronic structure and the binding energy of the interacting $\mathrm{As}_{\mathrm{Ga}}-\mathrm{As}_{\mathrm{i}}$ defect pair and a possible mechanism for the transformation into the metastable state has been put forward [17].

In this paper we retrace once again briefly the arguments which have led us to this attribution and report new experimental results on the atomic configuration of the metastable state. Finally, we will discuss the conflicting models proposed in the literature for this defect which, however, in our opinion, are unable to interprete all the experimental results reported so far for EL2 and the other intrinsic defects in GaAs.

\section{Experimental evidence for the complex structure of the EL2 related $A s_{\mathrm{Ga}}$ defect.}

Since the first quantitative correlation of the EL2 defect with the EPR observed $\mathrm{As}_{\mathrm{Ga}}$ defect [11], which at that time was believed to be an isolated defect, problems arose when the experimentally known properties were confronted with theoretical calculations. First, the energy level positions for the $0 /+$ state of the isolated $\mathrm{As}_{\mathrm{Ga}}$ defect were predicted to be much closer to the conduction band $\sim E_{\mathrm{c}}-$ $0.2 \mathrm{eV}$ [18] than the experimental value of $\sim E_{\mathrm{c}}-$ $-0.7 \mathrm{eV}$. Second, the important lattice relaxation associated with the metastability of EL2 was in contradiction to the well behaved small relaxation predicted for the isolated $\mathrm{As}_{\mathrm{Ga}}$ defect [19].

Further indication for a more complex structure of the EL2 defect was obtained from a comparison of the native $\mathrm{As}_{\mathrm{Ga}}$ and the electron irradiation induced $\mathrm{As}_{\mathrm{Ga}}$ defect [13]. Indeed, electron irradiation with electron of energies close to the threshold for single atomic displacement is a convenient technique to create simple intrinsic point defects selectively. The $\mathrm{As}_{\mathrm{Ga}}$ defect, which as a native defect is found in the
$10^{16} \mathrm{~cm}^{-3}$ concentration range, can be created at much higher concentration $\left(\sim 10^{18} \mathrm{~cm}^{-3}\right)$ with an introduction rate characteristic for a primary defect by electron irradiation of n-type GaAs. From various indications [20] such as the absence of the photoquenching effect, the more shallow $0 /+$ state, its formation mechanism and a normal electron phonon interaction as deduced from the temperature variation of the hyperfine interaction [21] we attributed the electron irradiation induced $\mathrm{As}_{\mathrm{Ga}}$ defect to the isolated $\mathrm{As}_{\mathrm{Ga}}-\mathrm{As}_{4}$ defect and in consequence the native $\mathrm{As}_{\mathrm{Ga}}$ defect to a more complex defect structure, labeled $\mathrm{As}_{\mathrm{Ga}}-\mathrm{X}$.

\section{Identification of $\mathbf{X}$.}

The identification of $\mathrm{X}$ with a weakly interacting interstitial As ion stems mainly from our combined DLTS and EPR results on the high temperature annealed samples [12, 13].

The samples needed for the DLTS studies were necessarily n-type conductive with a room temperature carrier concentration in the $10^{15} \mathrm{~cm}^{-3}$ range ; they were thus not suited directly for exploitation in an EPR experiment. Further, with a Fermi level pinned by the dopant Si donor level, all $\mathrm{As}_{\mathrm{Ga}}$ defects are in the 0 charge state at low temperature, which is diamagnetic and, consequently, not EPR observable. Therefore, for the EPR studies, the samples had to be compensated by electron irradiation with a low dose of $\sim 10^{15} \mathrm{~cm}^{-2}$.

The results were the following : $10 \mathrm{~min}$ annealing at $850{ }^{\circ} \mathrm{C}$ in forming gas $\left(\mathrm{N}_{2} / \mathrm{H}_{2}=9 / 1\right)$ with one side $\mathrm{Si}_{3} \mathrm{~N}_{4}$ encapsulated followed by a quench leads to a strong reduction $(\sim 10)$ in the EL2 concentration, as observed by DLTS, and the formation of an As rich surface region (22). Photo EPR measurements on the same samples - taken apart the electron compensation - showed the presence of an optically created $\mathrm{As}_{\mathrm{Ga}}^{+}$spectrum in the $5 \times 10^{15} \mathrm{~cm}^{-3}$ concentration range, which does not undergo a transition to the metastable state. Further thermal annealing in the $100^{\circ} \mathrm{C}$ temperature range leads to a partial regeneration of the original EL2 concentration $(20 \% \ldots 50 \%$ as observed by DLTS) with an activation energy of $\sim 0.5 \mathrm{eV}$ and renders the paramagnetic spectum once again metastable for a $1.2 \mathrm{eV}$ photoexcitation.

We interpreted these results in the following way : high temperature annealing under our experimental conditions breaks the $\mathrm{As}_{\mathrm{Ga}}-\mathrm{X}$ complex into its two components. They are partially regenerated at a temperature as low as $100^{\circ} \mathrm{C}$ - due to the mobility of the $\mathrm{X}$ component. A comparison of this low temperature atomic mobility, its activation energy of $0.5 \mathrm{eV}$ close to the one determined for the mobility of the arsenic interstitial in electron irradiated p-type GaAs [23] lead to the attribution of $X$ to the As 
interstitial ion. This attribution has recently been directly confirmed by ENDOR measurements on semi-insulating as grown GaAs [16].

\section{The atomic configuration in the stable and meta- stable state.}

Here the key information for the atomic configuration of the stable EL2 state comes from a comparison of the EPR spectra of the complexed and isolated $\mathrm{As}_{\mathrm{Ga}}$ defect. In particular the hyperfine interaction constant $\mathrm{A}$ is identical in the two cases within $\pm 5 \%$. This indicates that the associated $A s_{i}$ ion in EL2 is only weakly interacting with the paramagnetic $\mathrm{As}_{\mathrm{Ga}}^{+}$ion as otherwise this constant would have been substantially reduced. This is for example the case in the analogue defect system composed by the deep double donors $\mathrm{S}$ and $\mathrm{Se}$ in $\mathrm{Si}$, where both isolated S, Se and paired defects S-S, SeSe have been observed by EPR [24, 25]. This result is quantified by the ENDOR measurements, which place the $\mathrm{As}_{\mathrm{i}}$ ion at a $4.88 \mathrm{~A}$ distance in the antibonding [111] direction. They further indicate the $A s_{i}$ ion to be diamagnetic, that is in the + or charge states [16] : as concerns the charge state of the $\mathrm{As}_{\mathrm{Ga}}$ in the stable configuration of EL2 we have the following information from photo EPR measurements on samples with different Fermi level positions. In n-type semi-insulating samples, where the Fermi level lies above the $\mathrm{As}_{\mathrm{Ga}^{0}}{ }^{+}$level no EPR spectrum is observed when the sample is cooled in darkness to the liquid $\mathrm{He}$ temperature. If then this sample is photoexcited in the $1.2 \mathrm{eV}$ energy range a transient $\mathrm{As}_{\mathrm{Ga}}^{+}$is observable, corresponding to the different time constants for the photo-ionization cross-section and the transformation into the metastable state. Thus the $\mathrm{As}_{\mathrm{Ga}}^{0}-\mathrm{As}_{\mathrm{i}}$ is a stable configuration. The analogue observation can be made in ptype samples. Thus a stable EL2 configuration does exist for the three charge states $0,+, 2+$ of the $\mathrm{As}_{\mathrm{Ga}}$ defect.

Much less is known about the metastable configuration of EL2. Indeed, it has to be stressed that this state has not yet been observed directly by any experimental technique. Apparently it does not give rise to any paramagnetic spectrum. No optical absorption spectrum has been attributed to this state and it has not been observed in DLTS studies neither. Thus the question arises whether the metastable configuration contains any gap state at all. From the non observability of the $\mathrm{As}_{\mathrm{Ga}}$ EPR spectrum and $\mathrm{As}_{\mathrm{Ga}}^{0}$ optical absorption spectrum in the metastable configuration we concluded the formation of a close defect molecule, where the $\mathrm{As}_{\mathrm{i}}$ ion has been attracted by the substitutional $\mathrm{As}_{\mathrm{Ga}}$ defect. The contrary assumption, that is the formation of a more distant pair would lead to an even less perturbed $\mathrm{As}_{\mathrm{Ga}}$ defect, which is incompat- ible with the «non observation». For the close pair metastable configuration two microscopic models can be considered : the first one is a substitutionalinterstitial $\mathrm{As}_{\mathrm{Ga}}-\mathrm{As}_{\mathrm{i}}$ pair with $\mathrm{As} \mathrm{s}_{\mathrm{i}}$ in a first nearest neighbour position; the second one corresponds to the more symmetric configuration in which the two arsenic ions are symmetrically situated relative to the vacant gallium site. In fact, this last configuration corresponds to the coordination of the arsenic ions in amorphous arsenic [26] and only a slight lattice relaxation is necessary to reproduce the characteristic bond lengths and angles of the amorphous phase ; in this configuration the two central arsenic ions are threefold coordinated, the natural coordination of arsenic. It is further in agreement with the apparent absence of any deep gap state for EL2 in the metastable configuration (Fig. 2).

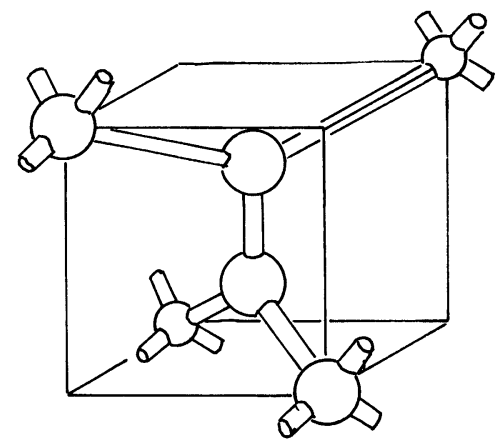

Fig. 2.

As concerns the driving force for the close pair formation there is some evidence that it is of Coulombic origin, even though it is not related to a simple photoionization process. In fact, electrical as well as EPR and optical studies of the stable $\rightarrow$ metastable transition show it to be a two step process. Optical excitation into the $1.2 \mathrm{eV}$ absorption band leads to a rapid photoionization of the $\mathrm{As}_{\mathrm{Ga}}^{0}{ }^{+}$charge states (at the time scale of seconds for $\mathrm{mW}$ excitation) ; it is followed by a slow transition into the metastable state ( $\sim 10 \mathrm{~min}$ time scale under the same conditions). One important result is that as the quenching of EL2 works efficiently in the space charge region of a reversed biased junction, where free carrier capture is negligeable, its origin can only be an internal transition, leading to a charge transfer between the $\mathrm{As}_{\mathrm{i}}$ and the $\mathrm{As}_{\mathrm{Ga}}$ ion : the only charge state configuration consistent with the model is :

$$
\begin{aligned}
\left(\mathrm{As}_{\mathrm{Ga}}^{0}-\mathrm{As}_{\mathrm{i}}^{+}\right)_{\text {stable }} & \rightarrow\left(\mathrm{As}_{\mathrm{Ga}}^{0}-\mathrm{As}_{\mathrm{i}}^{+}\right)_{\text {stable }}^{*} \rightarrow \\
& \rightarrow\left(\mathrm{As}_{\mathrm{Ga}}^{-}-\mathrm{As}_{\mathrm{i}}^{2+}\right)_{\text {metastable }} \rightarrow\left(\mathrm{As}_{2}^{+}\right)_{\text {metastable }} .
\end{aligned}
$$

This model is supported by the attribution of the $1.2 \mathrm{eV}$ quenching absorption band to an internal transition [9] and is in agreement with the recent calculation of G. Baraff et al. [17]. 


\section{Discussion of conflicting atomic models.}

Various other atomic models have been proposed before for the stable configuration of EL2. As will be outlined in the following they are often directly related with a particular experimental technique and in our opinion do not withstand a global confrontation with all known experimental results on EL2. We will not discuss in detail these models which range from a single point defect to an amorphous arsenic cluster in the order of increasing atomic complexity but only provide the experimental observations, they do not take into account.

A single point defect model for EL2 has been proposed by M. Kaminska et al. [27] who attributed it to the isolated arsenic antisite defect. Their basic argument was the splitting of the so-called «Zero Phonon Line » at $1.04 \mathrm{eV}$ under uniaxial stress, which they interpreted as a ${ }^{1} \mathrm{~A}_{1} \rightarrow{ }^{1} \mathrm{~T}_{2}$ transition of a defect in $T_{D}$ symmetry. This model contains however various weak points : high resolution optical absorption studies showed that this «Zero Phonon " line has a multiplet structure already in the absence of any applied uniaxial stress [28, 29]. Moreover, the intensity ratio between the zero phonon line and its phonon replica is inconsistent with the reported Huang-Rhys factor. In fact, the question arises whether this sharp line spectrum is related to the broad absorption band at $1.2 \mathrm{eV}$ at all ; correlations [30] and anticorrelations [28] between the zero phonon line intensity and the EL2 concentrations have been reported. Further, this model is in contradiction with the ENDOR data [16] on the EL2 related $\mathrm{As}_{\mathrm{Ga}}$ defect and the conclusion drawn from an EPR and DLTS results in thermally annealed and electron irradiated GaAs [12, 13].

A different model has been discussed by Lagowski et al. [28] who considered the arsenite antisite-arsenic vacancy defect. The main objection for it comes from the fact that this defect has already been observed by EPR in $\mathrm{e}^{-}$-irradiated GaAs [31] and displays a paramagnetic spectrum different from the one observed in as grown material. It is once again in contradiction with the ENDOR results [16], which showed the presence of four nearest neighbour arsenic ions and is finally also inconsistent with the calculated properties of this defect [32].

A still more complicated model has recently been proposed by Wager et al. [33]. They attributed the EL2 defect to an arsenic antisite-divacancy triple defect. The authors argue that the existence of the divacancy defects can be deduced from positon lifetime studies in as-grown GaAs [34]. However, the thermal stabilities of the supposed divacancy defects and of EL2 are very different. When the first one anneals out in the $450{ }^{\circ} \mathrm{C}$ temperature range, EL2 is known to be stable in the same temperature range. As to the proposed metastable configuration, essentially a $\mathrm{As}_{\mathrm{Ga}}-\mathrm{V}_{\mathrm{As}}$ defect pair perturbed by a $\mathrm{V}_{\mathrm{Ga}}$ vacancy, it is equally inconsistent with the EPR data reported for this defect complex.

Ikoma et al. [35] have introduced the EL2 family concept and proposed EL2 to be a defect in amorphous arsenic clusters supposed to be existing in all semi-insulating GaAs. However, this qualitative model, mainly derived from photocapacitance studies are not confirmed in optical or EPR studies.

\section{Conclusion.}

In conclusion, the microscopic model, which we proposed for the stable configuration of the EL2 defect, is in agreement with all experimental results so far known for this defect contrary to the other models discussed in the preceeding sections. Its direct confirmation by the reinterpreted ENDOR results obtained by B. K. Meyer et al. [16] has been an important achievement. Whereas the model for the atomic configuration of EL2 in the metastable state, that is a relaxed As-pair at a gallium lattice site, seems reasonable, it demands further experimental and theoretical support.

\section{References}

[1] Makram-Ebeid, S., Langlade, P. and Martin, G. M., Proc. 3rd Int. Conf. on Semi-Insulating 3-5 Materials, ed. by G. J. Rees (Shiva Publ., Nantwich, U.K.) 1984, p. 184.

[2] Martin, G. M. and Makram-Ebeid, S., Deep Centers in Semiconductors, ed. by S. Pantelides (Gordon \& Breach Sc. Publ., New York) 1986 p. 399.

[3] Martin, G. M., Mitonneau, A. and Mircea, A., Electron. Lett. 13 (1977) 191.

[4] Mitonneau, A., Mircea, A., Martin, G. M. and Pons, D., Rev. Phys. Appl. 14 (1979) 853.

[5] Prinz, V. Y. and RechKunov, S. N., 4th Int. Conf. on Deep Impurities in Semiconductors, EGER, Hungary (1985) unpublished.
[6] Chantre, A., Vincent, G. and Bois, D., Phys. Rev. B 23 (1981) 5335.

[7] Bois, D. and Vincent, G., J. Physique Lett. 38 (1977) L-351.

[8] Martin, G. M., Proc. 1st Int. Conf. on Semi-Insulating 3-5 Materials, ed. by G. J. Rees (Shiva Publ., Nantwich, U. K.) 1980, p. 13.

[9] KaMinSKa, M., SKowronsKi, M., LAgowsKi, J., Parsey, J. M. and Gatos, H. C., Appl. Phys. Lett. 43 (1983) 302.

[10] Wagner, R. J., Krebs, J. J., Strauss, G. M. and White, A. M., Solid State Commun. 36 (1980) 15.

[11] Elliot, K., Chen, R. T., Greenbaum, S. G. and Wagner, R. J., Appl. Phys. Lett. 44 (1984) 907. 
[12] von Bardeleben, H. J., Stievenard, D., BourgoIN, J. C. and Huber, A., Appl. Phys. Lett. 47 (1985) 970.

[13] von Bardeleben, H. J., Stievenard, D., DeresMES, D., Huber, A. and Bourgoin, J. C., Phys. Rev. B 34 (1986) 7192.

[14] Stievenard, D., von Bardeleben, H. J., BourGoIN, J. C. and Huber, A., " Defects in Semiconductors» Mater. Sci. Forum 10-12, ed. by H. J. von Bardeleben (Trans Tech Publ., Switzerland) 1986, p. 305.

[15] Hofmann, D. M., Meyer, B. K., Lohse, F. and Spaeth, J. M., Phys. Rev. Lett. 53 (1984) 1187.

[16] Meyer, B. K., HofmanN, D. M. and Spaeth, J. M., " Defects in Semiconductors » Mater. Sci. Forum 10-12, ed. H. J. von Bardeleben (Trans Tech Publ., Switzerland) p. 311, 1986.

[17] Baraff, G. A. and Schlüter, M., Phys. Rev. B 35 (1987) 5929.

[18] Baraff, G. A. and Schlüter, M., Phys. Rev. B 55 (1985) 1327.

[19] Bachelet, G. B. and Scheffler, M., Proc. of the 17th Int. Conf. on the Physics on Semiconductors, ed. by J. D. Chadi and W. A. Harrison (Springer Verlag, New York) 1985, p. 755.

[20] von BARdeleben, H. J., Miret, A., LiM, H. and Bourgoin, J. C., J. Phys. C 20 (1987) 1353.

[21] Mauger, A., von Bardeleben, H. J., Bourgoin, J. C. and LANnoo, M., Phys. Rev. B, to be published (1987).

[22] Alnot, P. and Bourgoin, J. C., unpublished.

[23] Stievenard, D., Boddaert, X. and Bourgoin, J. C., Phys. Rev. B 34 (1986) 4048.
[24] Wörner, R. and Schirmer, O. F., Solid State Commun. 51 (1984) 665.

[25] Weinert, C. M. and Scheffler, M., « Defects in Semiconductors », Mater. Sci. Forum 10-12, ed. H. J. von Bardeleben (Trans. Tech. Publ., Switzerland) 1986, p. 25.

[26] Lucovsky, G. and Knights, J. C.,Phys. Rev. B 10 4324 (1974).

[27] Kaminska, M., Skowronski, M. and Kuszko, W., Phys. Rev. Lett. 55 (1985) 2204.

[28] Lagowski, J. and Gatos, H. C., Defects in Semiconductors, ed. L. C. Kimerling and J. M. Parsey (The Metallurgical Soc. of AIME) 1985, p. 73.

[29] Manasreh, M. O. and Covington, B. C., Phys. Rev. B 35 (1987) 2524.

[30] Skowronski, M., Lin, D. G., Lagowski, J., PawLowicZ, L. M., Ko, K. Y. and Gatos, H. C., Microsc. Identif. of Elect. Def. in Semiconductor, ed. by N. M. Johnson, S. G. Bishop, G. D. Watkins (Mat. Res. Soc., Pittsburgh, USA) 1985, p. 207.

[31] von BARDEleben, H. J., Bourgoin, J. C. and Miret, A., Phys. Rev. B 34 (1986) 1360.

[32] Baraff, G. A. and Schlüter, M., Phys. Rev. Lett. 55 (1985) 2340.

[33] Wager, J. F. and van Vechten, J. A., Phys. Rev. B 35 (1987) 2330.

[34] Dannefaer, S. and Kerr, D., J. Appl. Phys. 60 (1986) 591.

[35] Iкома, T. and Mochizuki, Y., Jpn. J. Appl. Phys. 24 (1985) L 935. 